\title{
FULL REGENERATION OF SEGMENTAL BONE DEFECTS USING POROUS TITANIUM IMPLANTS LOADED WITH BMP-2 CONTAINING FIBRIN GELS
}

\author{
J. van der Stok ${ }^{1 *}$, M.K.E. Koolen ${ }^{1,2}$, M.P.M. de Maat ${ }^{3}$, S. Amin Yavari ${ }^{4}$, J. Alblas ${ }^{2}$, P. Patka ${ }^{5}$, J.A.N. Verhaar ${ }^{1}$, \\ E.M.M. van Lieshout ${ }^{6}$, A.A. Zadpoor ${ }^{4}$, H. Weinans ${ }^{2,4,7}$ and H. Jahr ${ }^{8}$
}

\author{
${ }^{1}$ Orthopaedic Research Laboratory, Department of Orthopaedics, Erasmus University, Medical Centre Rotterdam, \\ Rotterdam, The Netherlands \\ ${ }^{2}$ Department of Orthopaedics, University Medical Centre Utrecht, Utrecht, The Netherlands \\ ${ }^{3}$ Department of Haematology, Erasmus University Medical Centre Rotterdam, Rotterdam, The Netherlands \\ ${ }^{4}$ Department of Biomechanical Engineering, Delft University of Technology, Delft, The Netherlands \\ ${ }^{5}$ Department of Emergency Medicine, Department of Orthopaedics, Erasmus University Medical Centre Rotterdam, \\ Rotterdam, The Netherlands \\ ${ }^{6}$ Trauma Research Unit, Department of Surgery, Erasmus University Medical Centre Rotterdam, Rotterdam, \\ The Netherlands \\ ${ }^{7}$ Department of Rheumatology, University Medical Centre Utrecht, Utrecht, The Netherlands \\ ${ }^{8}$ Department of Orthopaedics Surgery, University Hospital RWTH Aachen, Aachen, Germany
}

\begin{abstract}
Regeneration of load-bearing segmental bone defects is a major challenge in trauma and orthopaedic surgery. The ideal bone graft substitute is a biomaterial that provides immediate mechanical stability, while stimulating bone regeneration to completely bridge defects over a short period. Therefore, selective laser melted porous titanium, designed and fine-tuned to tolerate full load-bearing, was filled with a physiologically concentrated fibrin gel loaded with bone morphogenetic protein-2 (BMP-2). This biomaterial was used to graft critical-sized segmental femoral bone defects in rats. As a control, porous titanium implants were either left empty or filled with a fibrin gels without BMP-2. We evaluated bone regeneration, bone quality and mechanical strength of grafted femora using in vivo and ex vivo $\mu \mathrm{CT}$ scanning, histology, and torsion testing. This biomaterial completely regenerated and bridged the critical-sized bone defects within eight weeks. After twelve weeks, femora were anatomically re-shaped and revealed open medullary cavities. More importantly, new bone was formed throughout the entire porous titanium implants and grafted femora regained more than their innate mechanical stability: torsional strength exceeded twice their original strength. In conclusion, combining porous titanium implants with a physiologically concentrated fibrin gels loaded with BMP-2 improved bone regeneration in load-bearing segmental defects. This material combination now awaits its evaluation in larger animal models to show its suitability for grafting loadbearing defects in trauma and orthopaedic surgery.
\end{abstract}

Keywords: BMP, bone graft, bone regeneration, fibrin, metal surface treatment, scaffold, titanium.

*Address for correspondence:

Johan van der Stok, MD

Room Ee1614, PO Box 2040, 3000 CA Rotterdam, The Netherlands

Telephone number: +31-10-7043384

Fax number: +31-10-7044690

E-mail: j.vanderstok@erasmusmc.nl

\section{Introduction}

A major challenge in trauma and orthopaedic surgery is to successfully repair load-bearing segmental bone defects (Einhorn, 1995). This often requires the use of bone grafts or bone graft substitutes to improve bone regeneration by providing an osteoconductive matrix, offering mechanical support, or an osteoinductive and/or osteogenic stimulus (Giannoudis et al., 2011). The golden standard bone graft is still autologous bone (Pape et al., 2010), but the amount of bone that can be harvested is limited and associated with complications in 10-40\% (Banwart et al., 1995). These disadvantages motivate the development of biomaterials that can be used as bone graft substitutes (Langer and Vacanti, 1993).

A biomaterial that has the potential to become a bone graft substitute is porous titanium (Alvarez and Nakajima, 2009; Murr et al., 2010; Ryan et al., 2006). Nowadays, porous titanium can be manufactured using additive manufacturing techniques such as selective laser melting (SLM) (Hollander et al., 2006). This enables the design of porous titanium so that its structure and mechanical strength remains suitable to function as a load-bearing osteoconductive matrix in segmental bone defects (Van der Stok et al., 2013a). Osseointegration of titanium is optimised through relatively simple chemical and heat treatments that alter the surface chemistry and (nano-) topography (Amin Yavari et al., 2014a). Thereby, the bioinert titanium surface changes into a bioactive surface that allows spontaneous apatite formation and stimulates proliferation and osteogenic differentiation of osteoprogenitor cells (Amin Yavari et al., 2014b). This surface-treated porous titanium forms a load-bearing osteoconductive matrix, but stimulating bone regeneration and adequate bridging of segmental bone defects may be further improved by addition of effective biological stimuli (i.e. osteoinductive cytokines) (de Wild et al., 2013; Van der Stok et al., 2013a).

Bone morphogenetic proteins (BMPs) such as BMP2 and BMP-7 play a major role in bone regeneration as osteoinductive cytokines (Urist, 1965). Their osteoinductive effects have been established in a wide range of species, 
varying from mice and rats to humans (Murakami et al., 2002). BMP-2 and BMP-7 have received USA Food and Drugs Administration (FDA) approval for use in trauma and orthopaedic surgery (Senta et al., 2009), but their clinical success is limited (Khan and Lane, 2004). This might be because a supra-physiological dosage of BMP needs to be loaded onto an absorbable collagen sponge to reach an effect (Termaat et al., 2005). This high dose has been associated with adverse effects including bone tissue overgrowth, ectopic bone formation, inflammation, and even carcinogenicity (Carragee et al., 2011; Woo, 2013). To overcome this, numerous slow-release systems have been developed. Interestingly, these slow-release systems, allowing for controlled release of BMP-2 during several weeks, do not resemble the natural bone regeneration process in which BMP-2 is mainly released during the first few days (Cho et al., 2002; Gerstenfeld et al., 2003).

Bone regeneration starts with the formation of a fibrin clot, often referred to as the fracture haematoma. This fibrin clot forms the natural binding reservoir for osteoinductive cytokines such as BMP-2 (Gerstenfeld et al., 2003; Martino et al., 2013) and is formed through conversion of fibrinogen by thrombin. Fibrinogen is synthesised in its high molecular weight form, but occurs as a mixture together with partially degraded low molecular weight forms in circulation (Kaijzel et al., 2006). Fibrin gels, made from physiological fibrinogen concentrations (2-4 mg/L), are highly permeable to cells (Kaijzel et al., 2006). However, at these physiological concentrations, fibrin gels are soft and therefore not suitable for most clinical applications. Consequently, commercially available fibrin sealants contain very high fibrinogen concentrations (50$100 \mathrm{mg} / \mathrm{L})$ (Janmey et al., 2009) at the cost of seriously compromising the favourable cellular permeability of these gels. When incorporated into porous titanium, the use of physiologically concentrated fibrin gels becomes feasible as the metal frame ensures mechanical support, then. The surface-treated porous titanium implants may even improve the network organisation of fibrin fibres (Milleret et al., 2011).

The aim of the current study was to develop a biomaterial capable of improving bone regeneration of segmental bone defects: osteoconductive load-bearing porous titanium filled with physiologically concentrated fibrin gels releasing BMP-2. For this novel combination, the BMP-2 releasing fibrin gel was prepared from purified high molecular weight (HMW) fibrinogen, since HMW fibrinogen increases angiogenesis in vitro and in vivo. (Kaijzel et al., 2006). To determine whether the angiogenic HMW fibrin gel alone is capable of increasing bone regeneration, porous titanium implants were also filled with HMW fibrin gels without BMP-2 and compared to unfractionated (UNF) fibrin gels. Porous titanium implants incorporated with the three above described fibrin gels were compared to empty porous titanium implants in a criticalsized load-bearing segmental femur defect in rats using in vivo (4, 8 and 12 weeks) and ex vivo (after 12 weeks) $\mu \mathrm{CT}$ scans, histology, and biomechanical torsion tests.

\section{Materials and Methods}

\section{Porous titanium implants}

Porous titanium implants were produced from Ti6Al4V ELI powder (ASTM B348, grade 23) using selective laser melting (SLM, Layerwise N.V., Leuven, Belgium). The implants were a copy of the replaced femoral bone segment and had a height of $6 \mathrm{~mm}$, a maximum outer diameter of $5 \mathrm{~mm}$ and a minimal inner diameter of $1.3 \mathrm{~mm}$ (leaving an open medullary canal). The porous architecture was based on a dodecahedron unit cell with a strut width of $120 \mu \mathrm{m}$ and an average pore size of $500 \mu \mathrm{m}$, to result in $55 \mathrm{~mm}^{3}$ porous volume. All implants underwent a post-production alkali-acid-heat treatment consisting of (1) immersion in a $5 \mathrm{M}$ aqueous $\mathrm{NaOH}$ solution at $60{ }^{\circ} \mathrm{C}$ for $24 \mathrm{~h}$; (2) immersion in water at $40{ }^{\circ} \mathrm{C}$ for $24 \mathrm{~h}$; (3) immersion in $0.5 \mathrm{mM} \mathrm{HCl}$ at $40{ }^{\circ} \mathrm{C}$ for $24 \mathrm{~h}$; (4) heating to $600{ }^{\circ} \mathrm{C}$ at a rate of $5^{\circ} \mathrm{C} / \mathrm{min}$ in an electric furnace at ambient air pressure, keeping the temperature at $600{ }^{\circ} \mathrm{C}$ for $1 \mathrm{~h}$, and subsequent natural cooling (Amin Yavari et al., 2014b). Reproducibility of porous implant architecture (e.g., pore size, titanium strut thickness and porosity) was verified by $\mu$ CT (SkyScan 1076; Bruker micro-CT N.V., Kontich, Belgium).

\section{Fibrin gel preparation}

Fibrin gel preparation was done as previously described (Holm et al., 1985; Kaijzel et al., 2006). Briefly, plasminogen-rich unfractionated human fibrinogen (Chromogenix, Mölndal, Sweden) was dissolved in Tris buffer $(10 \mathrm{mM}$ Tris/ $\mathrm{HCl}, \mathrm{pH} 7.4)$ to a concentration of $5 \mathrm{mg} / \mathrm{mL}$. Saturated $\left(\mathrm{NH}_{4}\right)_{2} \mathrm{SO}_{4}$ was slowly added to a final concentration of $19 \%(\mathrm{v} / \mathrm{v})$ and the solution was mixed for $30 \mathrm{~min}$ at room temperature prior to centrifugation for $10 \mathrm{~min}$ at $2,000 \times \mathrm{g}$. Repetition of this precipitation step resulted in a HMW fibrinogen pellet ( $99 \%$ purity), which were dissolved in $5 \mathrm{~mL}$ of saline $(0.9 \% \mathrm{NaCl})$ and then dialysed against M199 culture medium, as was the UNF fibrinogen. Purity was determined using standard non-reducing sodium dodecylsulphate polyacrylamide gel electrophoresis and concentrations were calculated using the molar extinction coefficient of fibrinogen (E1 \% $280 \mathrm{~nm}$ for fibrinogen is 15.8). The preparations were stored in single-use aliquots at $-80{ }^{\circ} \mathrm{C}$ until further use.

In a custom-made mould, the porous titanium implants were filled with $55 \mu \mathrm{L}$ of either HMW fibrinogen $(2 \mathrm{mg} /$ $\mathrm{mL}, \mathrm{HMW}-\mathrm{Fb}$ ) or UNF fibrinogen ( $2 \mathrm{mg} / \mathrm{mL}, \mathrm{UNF}-\mathrm{Fb}$ ) which were clotted with $0.5 \mathrm{IU} / \mathrm{mL}$ of thrombin (Global Siemens Healthcare, Erlangen, Germany) dissolved in a $4.5 \mathrm{mM}$ calcium chloride buffer (Baxter, Utrecht, Netherlands) in a 8.5:1 ratio. HMW fibrin gels with BMP2 (HWM-BMP-Fb) were made by adding $3 \mu \mathrm{g}$ BMP-2 (Shanghai Rebone Biomaterials Co., China) in $1 \mathrm{mM}$ saline solution to the HWM fibrinogen solution before clotting. Prior to implantation, after clotting the fibrin-filled implants were wrapped in Parafilm ${ }^{\circledR}$ and incubated for $15-18 \mathrm{~h}$ at $6{ }^{\circ} \mathrm{C}$ to allow completion of fibrin gelling. 


\section{Scanning electron microscopy (SEM)}

To determine filling efficacy and to characterise the structure of the fibrin networks polymerised from HMW and UNF fibrinogen, SEM was used as follows: implants were filled with fibrin gels and fixed in $3 \%$ glutaraldehyde for $24 \mathrm{~h}$ and rinsed with sodium phosphate buffer $(0.1 \mathrm{M}$, pH 7.2-7.4; Merck). Samples were then consecutively dehydrated in ascending alcohol concentrations (30, 50, 70 and $90 \% \mathrm{v} / \mathrm{v}$ ) with three final incubations in $100 \%$ ethanol for $10 \mathrm{~min}$ each. Probes were critical-point-dried in liquid $\mathrm{CO}_{2}$ and then sputtered with a $30 \mathrm{~nm}$ gold layer. Samples were analysed in FEI/Philips XL 30 FEG ESEM (Philips) in a high vacuum environment.

\section{Load-bearing segmental bone defects}

Critical-sized segmental bone defects were made in the femora of 40 male 16-weeks-old Wistar rats (446 \pm 32 g). Rats were divided into four experimental groups receiving porous titanium implants filled with HMWBMP-Fb, HMW-Fb and UNF-Fb or were left empty (empty). The Animal Ethics Committee of the Erasmus University approved the study and Dutch guidelines for care and use of laboratory animals were followed. Before surgery, rats received subcutaneous injections of antibiotics (enrofloxacin, $5 \mathrm{mg} / \mathrm{kg}$ body weight) and pain medication (buprenorphine, $0.05 \mathrm{mg} / \mathrm{kg}$ body weight). Surgery was performed aseptically under general anaesthesia (1-3.5\% isoflurane). The right femur was exposed through a lateral skin incision and separation of underlying fascia. Using three proximal and three distal screws, a $23 \times 3 \times 2 \mathrm{~mm}$ polyether ether ketone (PEEK) plate (RISystem, Davos Platz, Switzerland) was fixed to the femur anterolateral plane. Periosteum was removed over $8 \mathrm{~mm}$ of the middiaphyseal region before a $6 \mathrm{~mm}$ cortical bone segment was removed with a wire saw and a tailor-made saw guide. Subsequently, a porous titanium implant was implanted press-fit into the defect. Finally, fascia and skin were sutured. Subcutaneous injection of pain medication (buprenorphine, $0.05 \mathrm{mg} / \mathrm{kg}$ body weight) was given twice a day for the following three days. Rats were sacrificed after twelve weeks with an overdose of pentobarbital (200 mg/ $\mathrm{kg}$ body weight).

\section{$\mu \mathrm{CT}$ evaluation}

Bone regeneration was measured by in vivo $\mu \mathrm{CT}$ scans (SkyScan 1076; Bruker micro-CT N.V., Kontich, Belgium) at four, eight and twelve weeks, and by ex vivo $\mu \mathrm{CT}$ scans on isolated grafted femora at the end of the experiment. Rats were kept under general anaesthesia (1-3.5\% isoflurane) during in vivo $\mu \mathrm{CT}$ scans at $35 \mu \mathrm{m}$ resolution (95 kV, $105 \mu \mathrm{A}$ current, $1.0 \mathrm{~mm} \mathrm{Al} / 0.25 \mathrm{~mm} \mathrm{Cu}$ filter, and $0.75^{\circ}$ rotation step, 14 min scan). Ex vivo $\mu \mathrm{CT}$ scans were acquired at $18 \mu \mathrm{m}$ resolution $(95 \mathrm{kV}, 100 \mu \mathrm{A}$ current, $1.0 \mathrm{~mm} \mathrm{Al} / 0.25 \mathrm{~mm} \mathrm{Cu}$ filter, and $0.5^{\circ}$ rotation step). $\mu \mathrm{CT}$ scan images were reconstructed using volumetric reconstruction software NRecon version 1.6.6 (Bruker micro-CT N.V., Kontich, Belgium).

Bone regeneration was expressed as bone volume (BV), which was measured at four specific regions: 1) total BV: the total volume of bone formed within the $6 \mathrm{~mm}$ defect;
2) porous BV: the bone formed inside the porous space of the titanium implants; 3 ) outer BV: the bone formed outside the porous titanium implants; and 4) inner BV: the bone formed in the medullary canal of the implants. BV values were measured using CTAnalyser version 1.13 (Bruker micro-CT N.V., Kontich, Belgium). First the specific region was selected, then the titanium and its border artefacts was excluded from images using a global threshold with a value between titanium and bone and removal of an extra $35 \mu \mathrm{m}$ border (size of one pixel) surrounding the titanium. Subsequently the bone was extracted by using a second global threshold that differentiated between bone and soft tissue. The global threshold values were chosen on visual inspection and were kept constant for all scans. Bone bridging was assessed on ex vivo scans with DataViewer 1.4 (Bruker micro-CT N.V., Kontich, Belgium). Complete bone bridging was defined as bridging of three or more cortices counted on ex vivo scans in the coronal and sagittal plane. Bone bridging was quantified by measuring the shortest remaining gap size between bone formed at the proximal and distal site of the $6 \mathrm{~mm}$ bone defect.

\section{Histological evaluation}

Histology was performed on two femora per group that represented the mean of the whole group. To select these two femora, all ten grafted femora were sorted according to their total BV after twelve weeks and the two femora closest to the averaged value were chosen. Harvested femora were fixed in $10 \%$ neutral buffered formalin solution for two days, dehydrated in ascending alcohol concentrations (70 to $100 \% \mathrm{v} / \mathrm{v}$ ), and finally embedded in methyl methacrylate (MMA). Sections of $\sim 20 \mu$ m were obtained using a diamond saw (Leica SP1600, Rijswijk, The Netherlands) and stained with basic fuchsin $0.3 \%$ $(\mathrm{w} / \mathrm{v})$ solution and methylene blue $1 \%(\mathrm{w} / \mathrm{v})$ solution to stain bone purple and fibrous tissue blue, respectively. Serial sections were then screened for bone formation, bone-implant contact and bone bridging.

\section{Biomechanical tests}

Mechanical strengths of grafted femora were measured by a torsion test conducted on the remaining eight femora of each group. Three contralateral femora, serving as a reference of intact femora, were included as controls. After harvesting the femora, soft tissues and PEEK plates were carefully removed. Specimens were kept in $10 \%$ neutral buffered formalin solution for two days, minimising the effects of formalin conservation on mechanical properties (Unger et al., 2010), and then transferred to phosphate buffered saline. Subsequently, both ends of each femur were embedded in a cold-cured epoxy resin (Technovit 4071, Heraeus Kulzer, Germany). On the upper clamping side, a Cardan joint was used to ensure pure rotation without bending. The lower sides were simply fixed. Tests were performed until failure with a rotation rate of $0.5^{\circ} \mathrm{s}^{-1}$ using a static mechanical testing machine that could apply a maximum torque of 450 N.mm (Zwick GmbH, Ulm, Germany). Torsional strength (maximum torque to failure, N.mm) was determined. 


\section{Statistics}

Statistical analyses were performed using SPSS Statistics 20.0 (SPSS, Inc.). Data are presented as means with standard deviations. One-way analysis of variation (ANOVA) and subsequent post hoc pairwise comparisons with Bonferroni adjustment were used to test for differences between the four groups. A power calculation $(\beta$-value $>0.80$, $\mathrm{SD} \sim 25 \%$ ) was made to find a true difference in total BV of at least $35 \%$. Based on this calculation, $n=10$ was required. A $p<0.05$ was considered statistically significant.

\section{Results}

\section{Porous titanium implants incorporated with fibrin gels}

Porous titanium implants were produced using SLM in the anatomical shape of the surgically removed cortical bone segment (Fig. 1a). The implants had a porosity of $85 \%$ and a pore size ranging from 460-670 $\mu \mathrm{m}$ (Table 1). The alkali-acid-heat treatment resulted in a titanium oxide layer with an irregular nano-scale features (Table 1). Macroscopic inspection and SEM analyses verified that the pores of the titanium implants were completely filled with fibrin gel (Fig. 1a-b). The protein fibres of both fibrin gels attached intimately to the surface-treated titanium (Fig. 1c). In addition, SEM showed clear differences between $\mathrm{HMW}-\mathrm{Fb}$ and UNF-Fb gels with respect to their nanofiber structures: as compared to the fibre network formed by unfractionated fibrinogen, resulting in a much denser structures with smaller average pore diameters and
Table 1. Properties of porous titanium implants (Amin Yavari et al., 2014b; Van der Stok et al., 2013a).

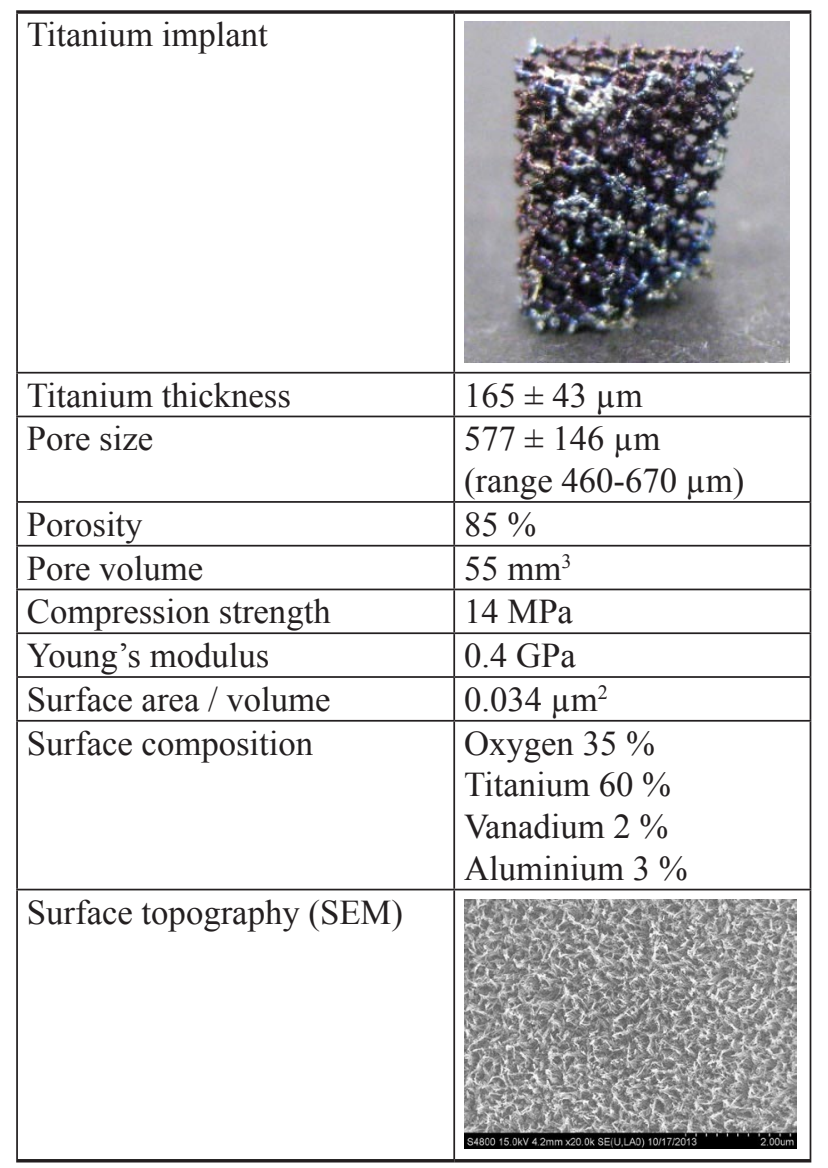
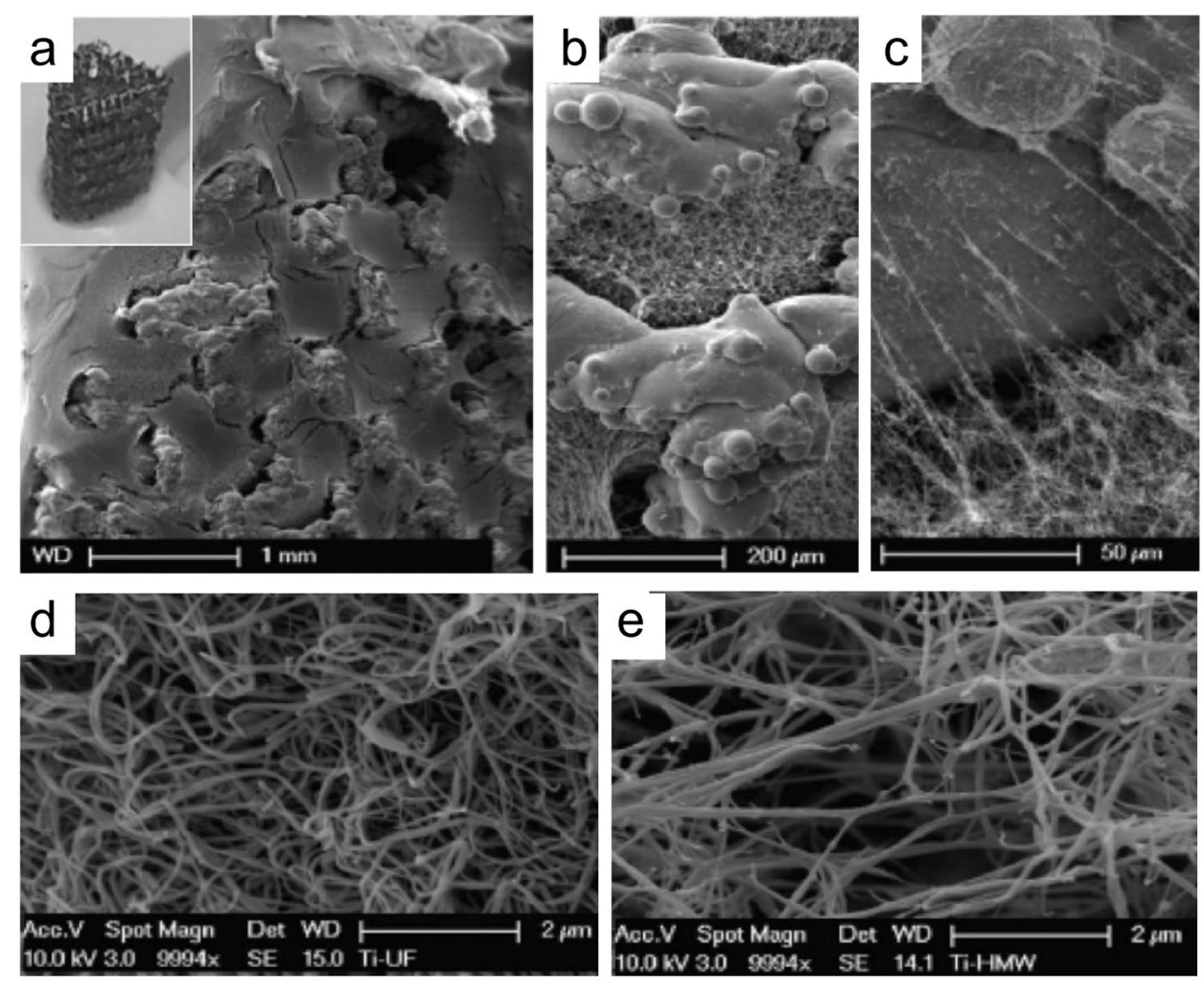

Fig. 1. SEM images of fibrin loaded porous titanium implants. Macroscopic overview, and enlarged details, of a fully fibrin-filled implant (a, b). The fibrin fibres are tightly bound to the implant surface (c). The fibre network resulting from unfractionated fibrinogen is rather dense with thin fibres (d). The fibrin network from HMW fibrinogen reveals a more-open, better-permeable, structure with slightly thicker fibres (e). 

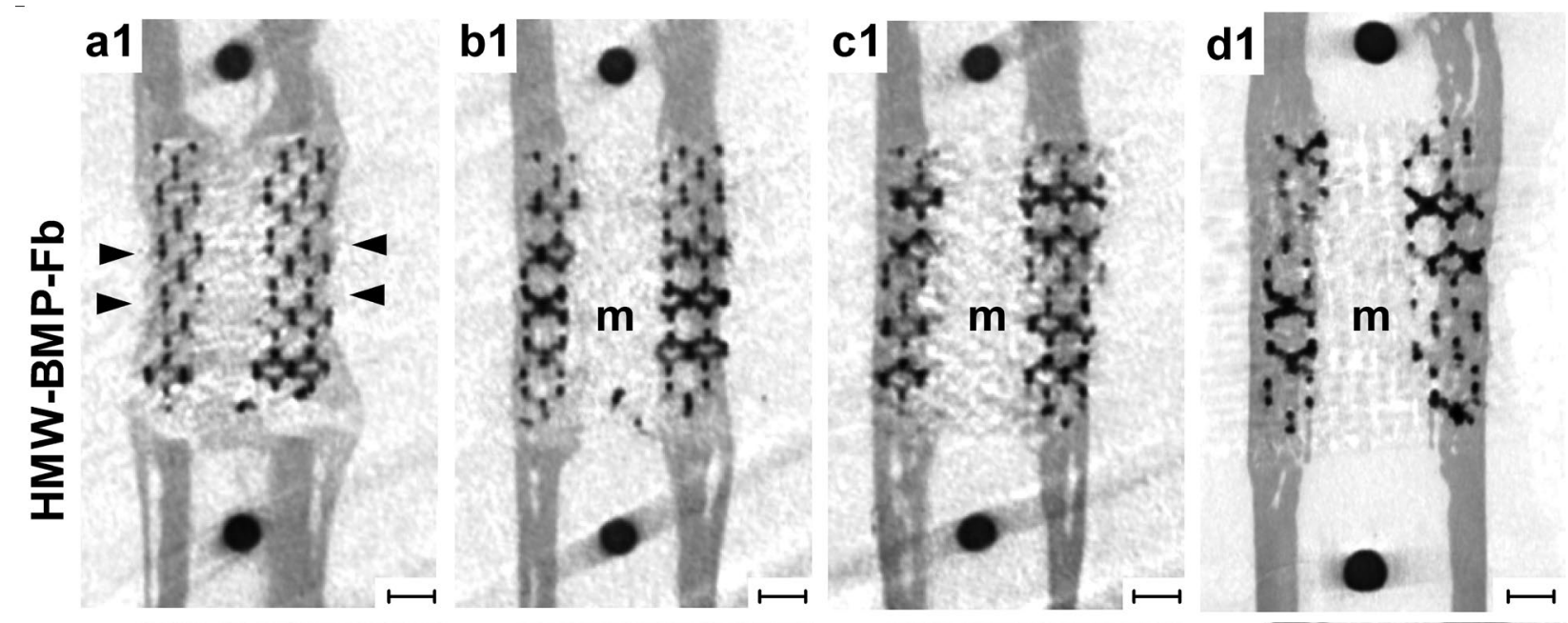

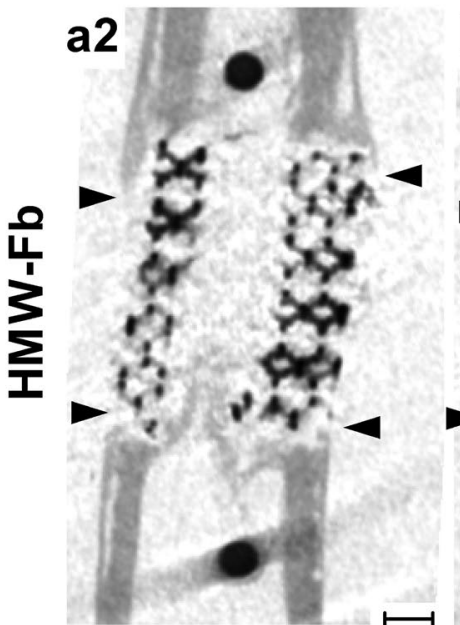

4 weeks

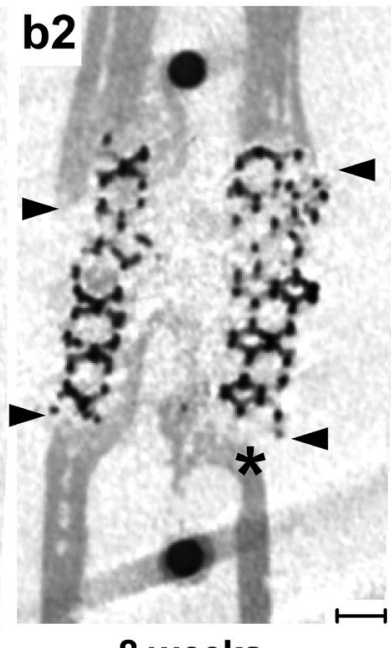

8 weeks

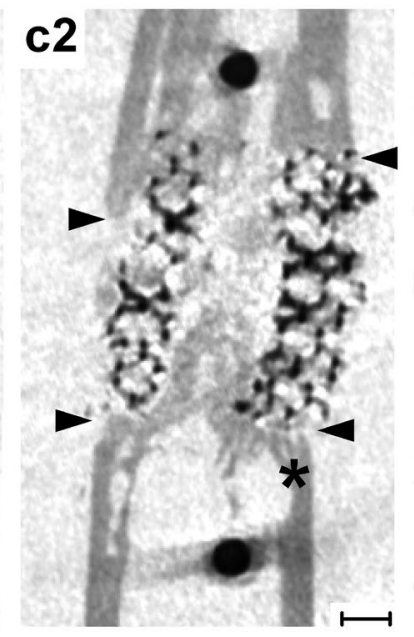

12 weeks

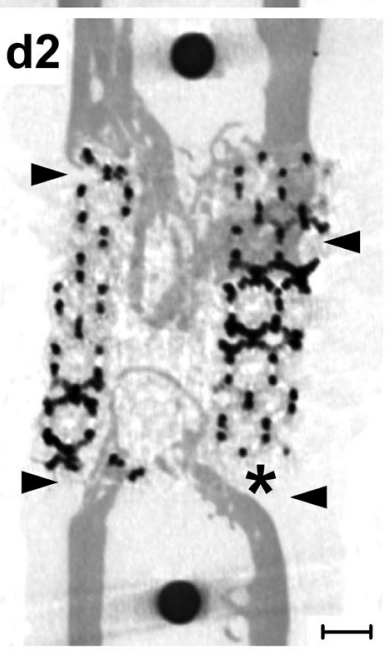

12 weeks

Fig. 2. Representative longitudinal $\mu \mathrm{CT}$ scans illustrating the bone regeneration process. In vivo scans of defects grafted with porous titanium implants incorporated with high molecular weight fibrin with BMP-2 (HMW-BMP-Fb group) and high molecular weight without BMP-2 (HMW-Fb group) after four (a1-2), eight (b1-2) and twelve weeks (c1-2) as well as ex vivo after twelve weeks (d1-2). In the HMW-BMP-Fb group, rapid bone regeneration throughout the complete length of the defect is already observed after four weeks (a1, arrows). Between eight and twelve weeks, the cortex and medullary canal (indicated by ' $\mathrm{m}$ ') are restored in their original shape (b1, c1, and d1). In the HMW$\mathrm{Fb}$ group, bone regeneration is only observed at the proximal and distal side of the porous implants (a2, arrows); this bone is predominantly situated in the medullary canal and insufficiently bridging the defect (d2). Distally from the titanium implants, bone resorption is observed between eight and twelve weeks (asterisk). Bar indicates $1 \mathrm{~mm}$.

thinner fibres (Fig. 1d), polymerisation of high molecular weight fibrinogen appeared to form a more open network with relatively thicker fibres (Fig. 1e).

\section{Load-bearing segmental bone defects}

All rats were able to tolerate weight-bearing activities immediately after surgery; the implantation sites healed without complications and all animals remained healthy during the follow-up.

\section{$\mu \mathrm{CT}$ evaluation}

Porous titanium implants with HMW-BMP-Fb gels effectively stimulated bone regeneration (Fig. 2). Within four weeks, bone regeneration had occurred throughout the entire length of the porous titanium implants and after eight weeks, bridging of the defect was complete.
Only minimal bone regeneration was observed in those defects grafted with HMW-Fb containing porous titanium implants and consequently failed to bridge (Fig. 2). The load-bearing segmental defects grafted with HMW-BMP$\mathrm{Fb}$ containing porous titanium implants fully restored the original bone architecture after twelve weeks (Fig. 2 and 3 ). Incorporation of $\mathrm{HMW}-\mathrm{Fb}$ or UNF-Fb did not seem to outperform the empty porous titanium implants (Fig. 3).

Quantitative analysis of regenerated bone, based on in vivo $\mu \mathrm{CT}$ scans, showed that the total BVs of the HMW-BMP-Fb group increased at each time point and reached an average of $65.1 \pm 14.9 \mathrm{~mm}^{3}$ after twelve weeks (Fig. 4a). This was significantly higher than all the three control groups. Neither the total BV of the HMW$\mathrm{Fb}\left(37.7 \pm 26.4 \mathrm{~mm}^{3}\right)$ group nor that of the UNF-Fb $\left(32.1 \pm 13.4 \mathrm{~mm}^{3}\right)$ group was significantly different from 

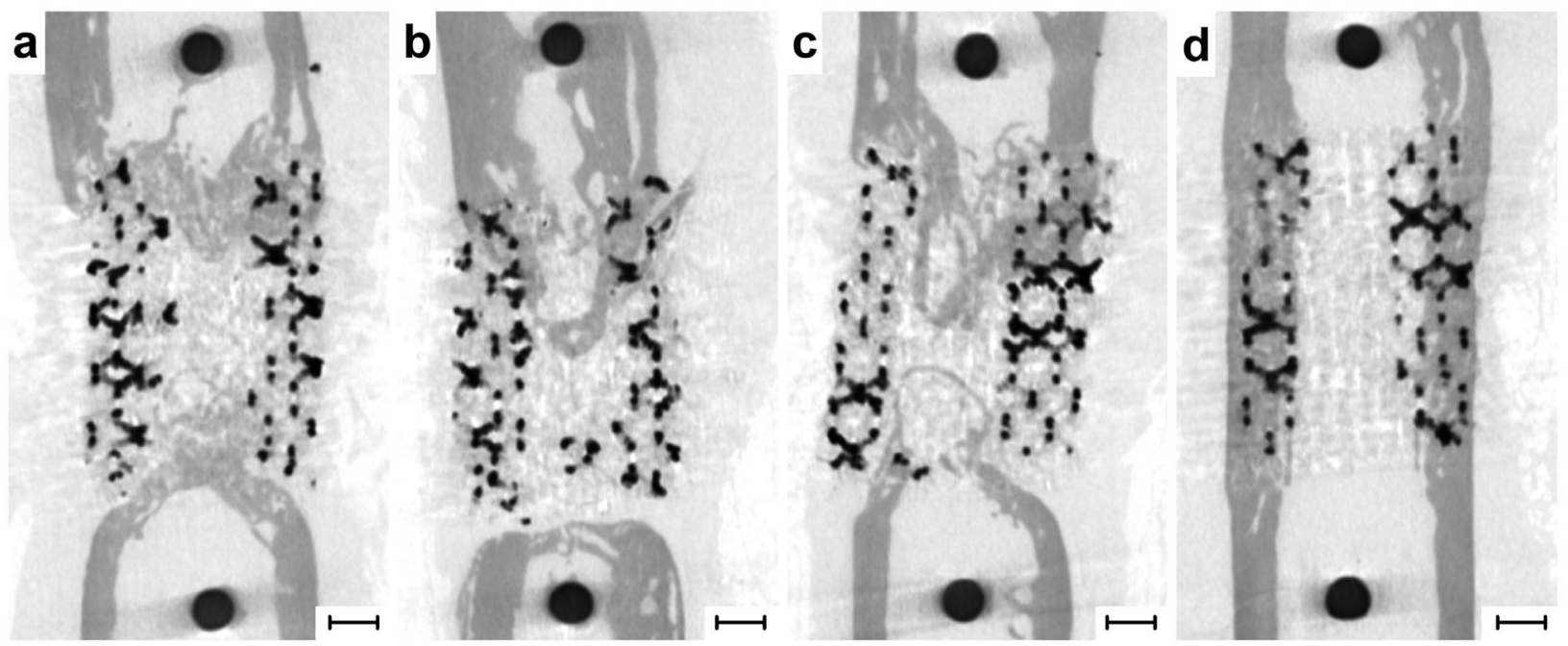

Fig. 3. Representative transversal ex vivo $\mu \mathrm{CT}$ images of grafted segmental femur defects. Titanium implants and fixation screws appear in black, whereas bone appears in dark grey. In the empty (a), UNF-Fb (b) and HMW-Fb (c) groups; bone regeneration is predominantly seen at the proximal and distal third of the porous titanium implants. Some new bone has formed inside the porous implants, but most of the newly formed bone is seen in the medullary canal. In the HMW-BMP-Fb group (d), bone regeneration extended throughout the entire porous titanium implants, bridging the defect. Bone formed inside the porous implant, and no bone has been formed inside the medullary canal. Black bar indicates $1 \mathrm{~mm}$.

the total BV of the empty group $\left(33.7 \pm 16.8 \mathrm{~mm}^{3}\right)$ (Fig. 4a). Also, the porous BV and outer BV of the HMW-BMP$\mathrm{Fb}$ group were significantly higher than that of all three control groups (Fig. 4b-c). After twelve weeks, $51 \pm 8 \%$ of the available pore space of the titanium implants with HMW-BMP-Fb gels was filled with regenerated bone, twice as much as in the HMW-Fb $(24 \pm 18 \%)$ and UNF-Fb $(21 \pm 5 \%)$ group, respectively. The inner BV of the HMWBMP-Fb group $\left(3.9 \pm 1.6 \mathrm{~mm}^{3}\right)$ significantly increased as compared to the control groups after four weeks. Contrary to the HMW-Fb and UNF-Fb groups, the inner BV of the HMW-BMP-Fb decreased over time $\left(3.1 \pm 1.3 \mathrm{~mm}^{3}\right.$ at 8 weeks and $2.6 \pm 1.3 \mathrm{~mm}^{3}$ at 12 weeks) and even became significantly less than in the inner BV of the HMW-Fb group (Fig. 4d).

Bone bridging, determined on ex vivo $\mu \mathrm{CT}$ scans at twelve weeks, was only seen in the cortical defects grafted with porous titanium implants filled with HMW-BMP-Fb gels (Fig. 5). Seven defects were completely bridged, and the average remaining gap size in the three defects that were not bridged was $0.8 \pm 0.1 \mathrm{~mm}$ (Fig. 6a). The remaining gap size in the other three experimental groups was $1.8 \pm 1.6 \mathrm{~mm}$ (HMW-Fb group), $1.9 \pm 0.9 \mathrm{~mm}$ (UNF$\mathrm{Fb}$ group) and $1.8 \pm 1.4 \mathrm{~mm}$ (empty group), respectively.

\section{Histological evaluation}

Bone quality, assessed using light microscopy, showed that in the HMW-BMP-Fb group bone was formed almost exclusively at the site of the original cortex and an intimate contact between the regenerated bone and the titanium implant was found throughout the entire length of the defect (Fig. 7d vs. a-c). In the HMW-Fb (Fig. 7c), UNF$\mathrm{Fb}$ (Fig. 7b) and empty groups (Fig. 7a), bone formation occurred predominantly at the distal and proximal sites of the titanium implants that were close to the adjacent cortical bone. This bone formation never extended throughout the entire length of the porous implant. The remaining gaps in the defects were rather filled with amorphous fibrous tissue (Fig. 7a, b, and c). Strikingly, in the HMW-BMP-Fb group an open medullary canal was observed after twelve weeks (Fig. 7d), whereas in all control groups bone formation was blocking the medullary canal (Fig. 7a-c).

\section{Biomechanical evaluation}

Femora of the HMW-BMP-Fb group reached a significantly higher maximum torque than the three control groups (Fig. $6 \mathrm{~b})$. The specimens were more than twice as strong as control femora $(248 \%)$ and six femora of this HMW$\mathrm{BMP}-\mathrm{Fb}$ group were able to resist the maximum torque (450 N.mm) without breaking. Femora of the HMW-Fb group did not differ in maximum torque from the femora of the UNF-Fb or empty group. The average maximum torques were $60 \%$ (HMW-Fb group, $86 \pm 29$ N.mm), $51 \%$ (UNF-Fb group, $75 \pm 20$ N.mm), and $53 \%$ (empty group, $77 \pm 53$ N.mm), respectively, of the average maximum torque measured for control femora (146 \pm 19 N.mm) (Fig. 6b).

\section{Discussion}

An ideal biomaterial, that can be used as a bone graft substitute, should be able to fully regenerate and bridge load-bearing segmental bone defects within a short period of time (Langer and Vacanti, 1993). Our combination of surface-treated porous titanium with BMP-2 containing 
a

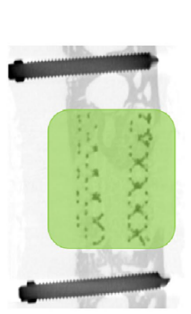

C

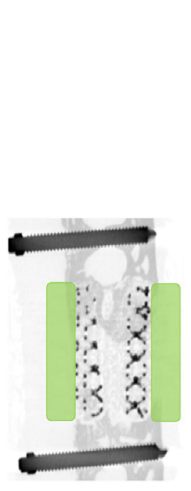

total BV

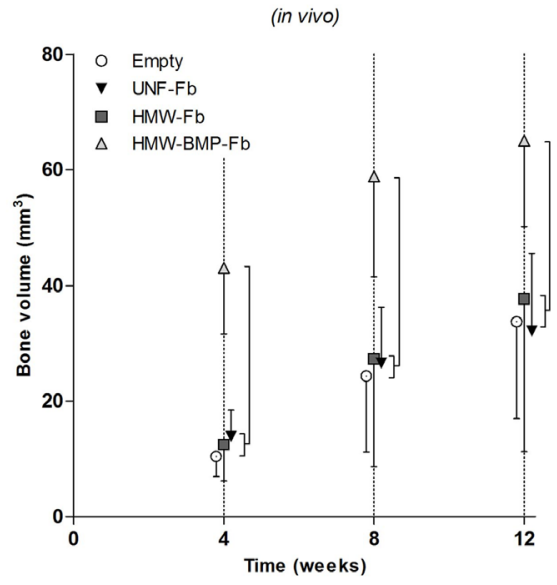

$\underset{\text { (in vivo) }}{\text { outer BV }}$

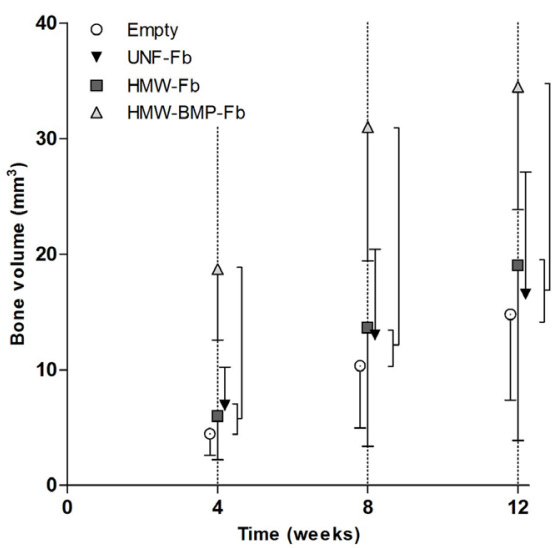

b
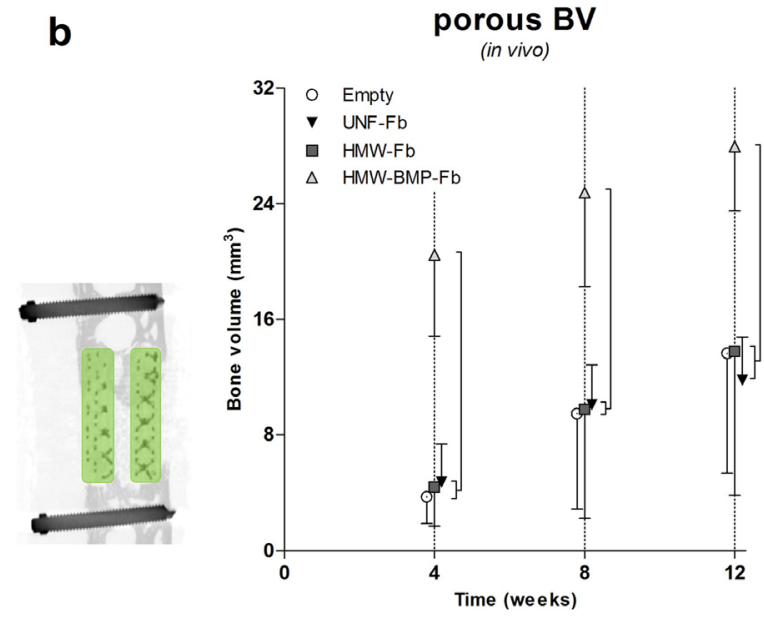

d

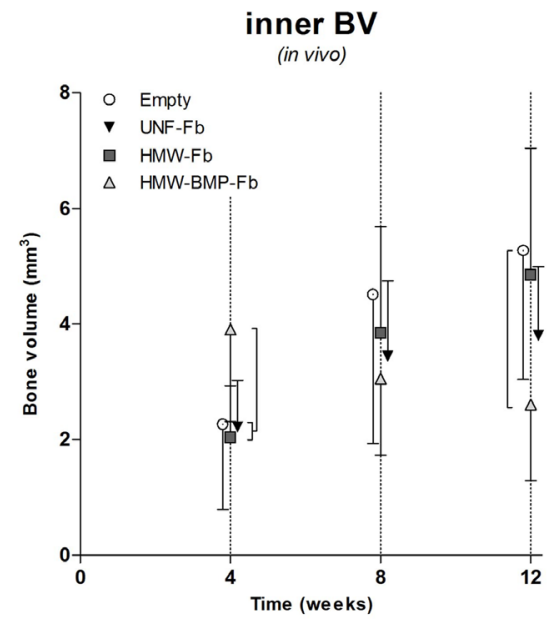

Fig. 4. Longitudinal quantification of bone regeneration. In vivo $\mu \mathrm{CT}$ scans after four, eight and twelve weeks; total BV (a); defined as all bone formed within the $6 \mathrm{~mm}$ defect. Outer BV (b), defined as bone formed outside the titanium implants. Porous BV (c), defined as bone formed inside the porous space of the titanium implants. Inner BV (d), defined as bone formed in the medullary canal of the titanium implants. Values are expressed as mean and SD ( $n=10$ per group), and a one-way ANOVA test followed by a post-hoc Bonferroni correction was performed to test for statistical significant difference at each time point; $p<0.05$ was considered as statistically significant, vertical bars indicate the significant differences found between the groups.
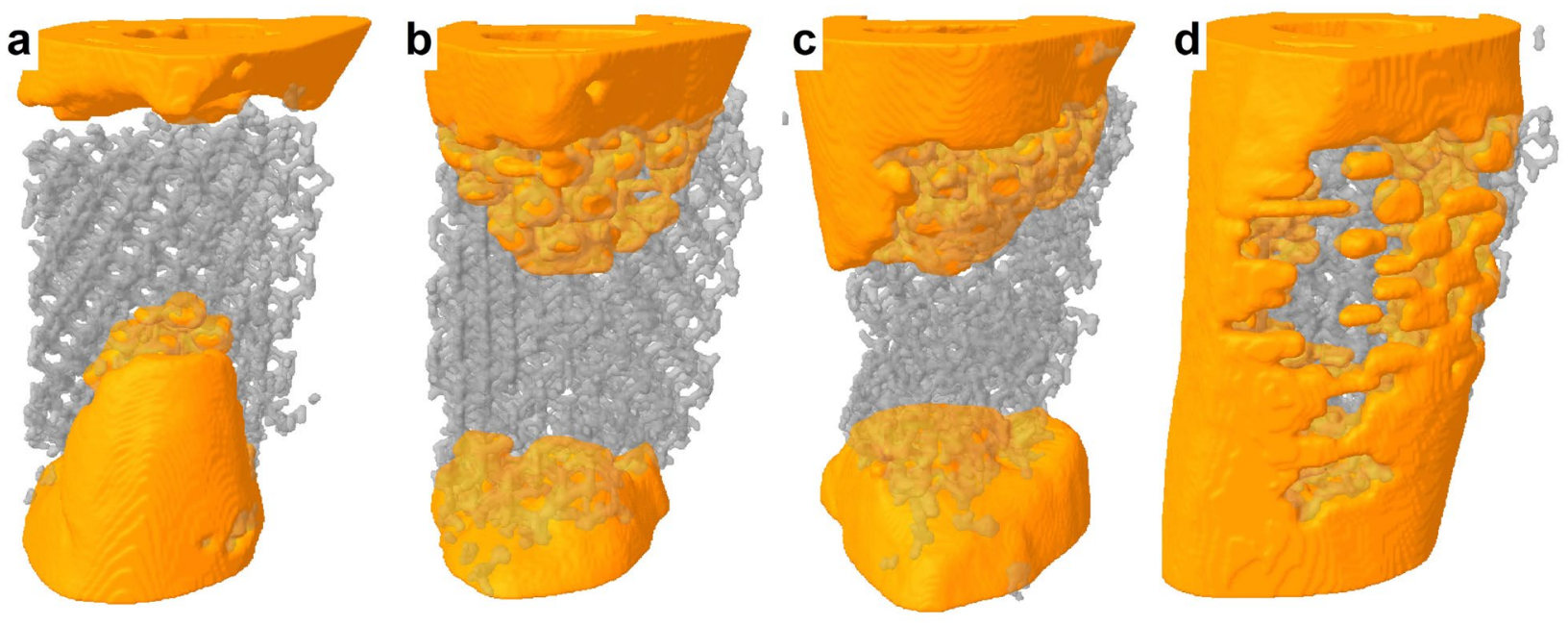

Fig. 5. Illustration of bone bridging. Representative 3D $\mu \mathrm{CT}$ images showing the average extend of bone bridging of the empty (a), UNF-Fb (b), HMW-Fb (c), as well as the HMW-BMP-Fb (d) group. Porous titanium implants appear in transparent grey, whereas bone appears in yellow/dark grey. 


\section{a Bone bridging}

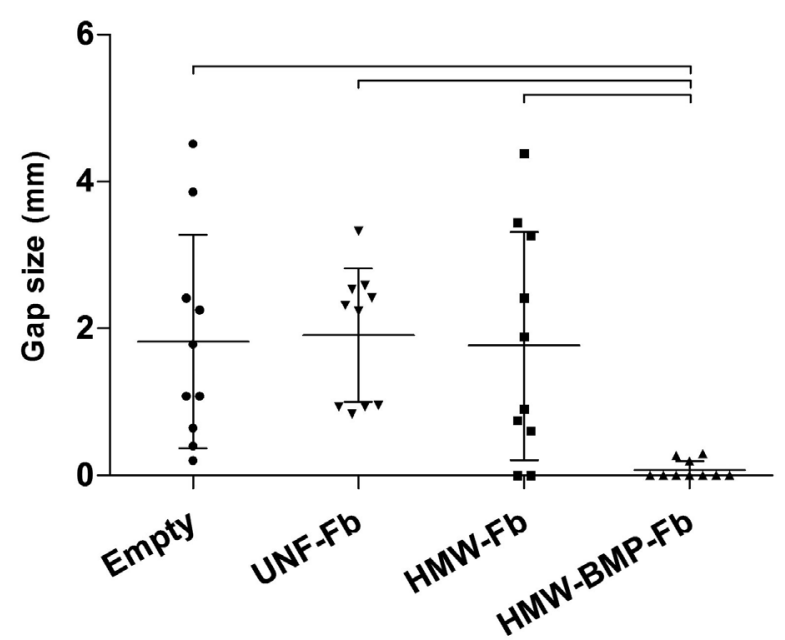

Fig. 6. Bone bridging and mechanical strength. The remaining gap size after twelve

b

Torsion testing weeks was used to indicate bridging success (a). Mechanical femoral strength after implantation of porous titanium implants measured by torsion testing (b). As a positive control, three control femora were included to provide a reference of a normal strength of femora during torsion testing (b, control). Values are expressed as mean and SD, and a one-way ANOVA test followed by a posthoc Bonferroni correction was performed to test for statistical significant differences at each time point; $p<0.05$ was considered as statistically significant, horizontal bars indicate significant differences between groups.
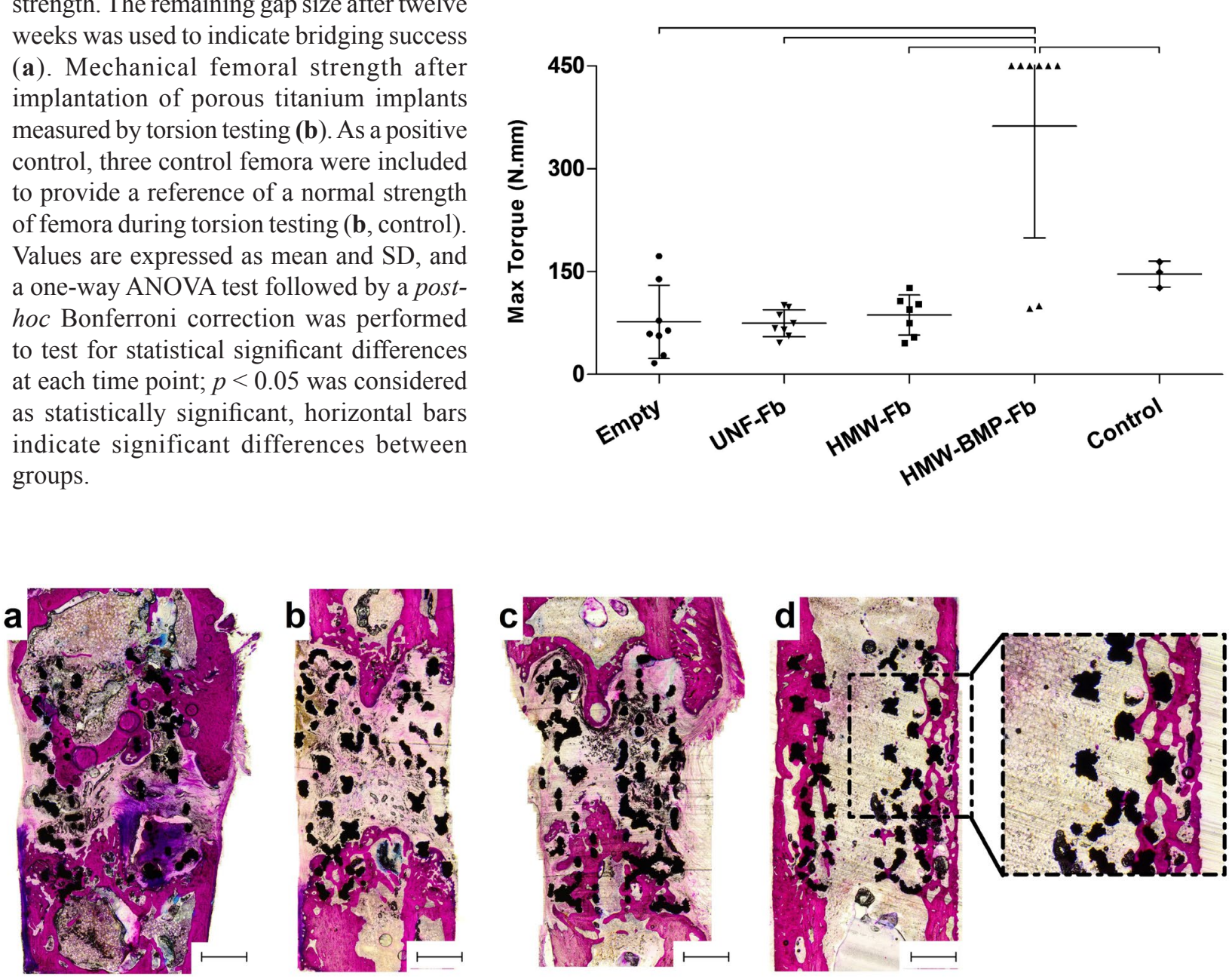

Fig. 7. Histological evaluation of bone bridging. Representative transversal sections of femur defects twelve weeks after implantation of porous titanium implants; empty (a), or incorporated with UNF-Fb (b), HMW-Fb (c) or HMWBMP-Fb gels (d). Magnification reveals re-colonisation of the medulla with small round-shaped cells of a typical bone marrow stroma appearance. Sections are stained with basic fuchsin and methylene blue. Basic fuchsin stains bone purple, methylene blue stains fibrous tissue blue. Black bar indicates $1 \mathrm{~mm}$. 
Fig. 8. Direct comparison between BMP-2 release from fibrin and gelatin on bone regeneration. In the same in vivo model, using the same type of porous titanium implants and same batch of BMP-2, results from using HMW-BMP-Fb gels (this work) or gelatin nanosphere gels (Van der Stok et al., 2013b) were compared. Using gelatin nanosphere gels loaded with $3 \mu \mathrm{g}$ BMP-2 predominantly led to bone regeneration outside or inside the porous titanium implants (a1) without bridging the entire defect (b1). In contrast, HMW-BMP$\mathrm{Fb}$ gels (loaded with the same dose of BMP-2) led to complete bridging with restoration of the medullary canal (a2) and the cortex (b2). Bar indicates $1 \mathrm{~mm}$.

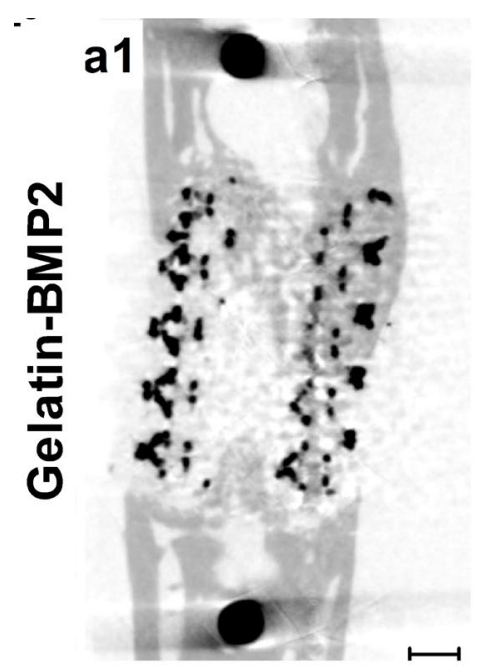

b1
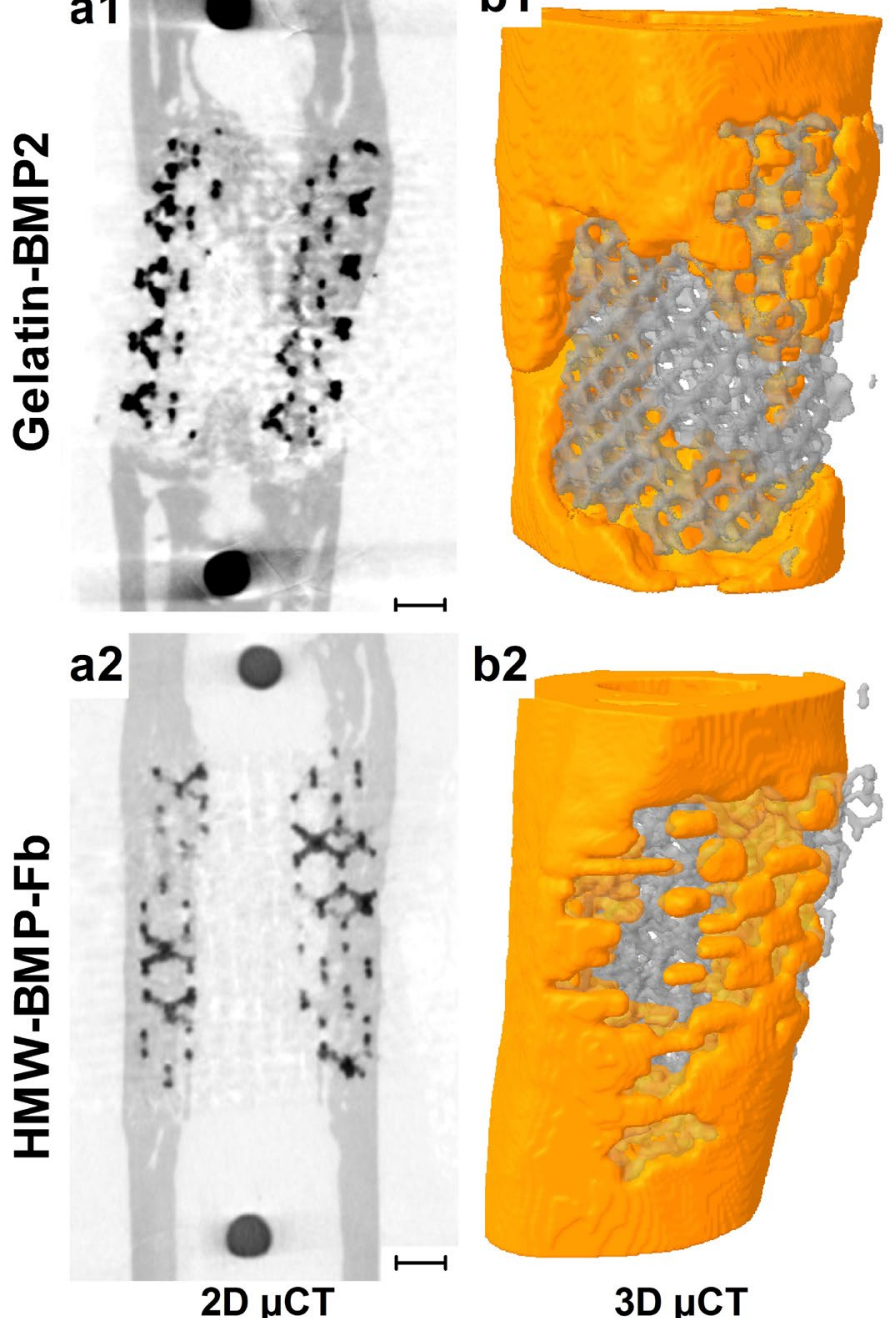

b2

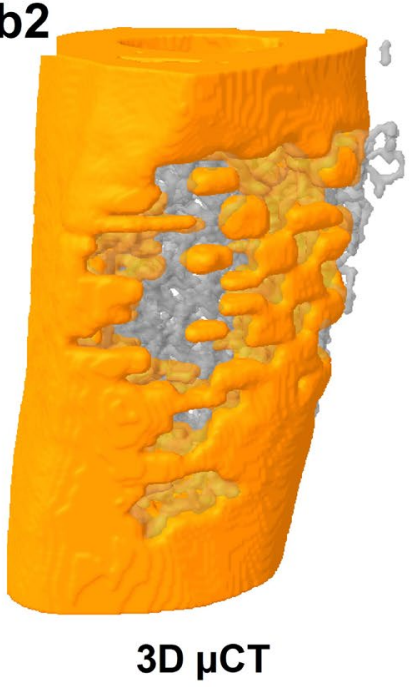

physiologically concentrated fibrin gels fully regenerated segmental bone defects in rat femora (Fig. 2 and 5) and fully recovered their mechanical strength (Fig. 6). Moreover, combining osteoconductive titanium with an osteoinductive BMP-2 releasing fibrin gel resulted in "guided" bone regeneration; i.e. new bone was formed throughout the porous titanium implants (Fig. 2) to specifically restore the cortex to its native anatomical shape as well as the medullary canal (Fig. 3 and 7d).

Biomaterials used for load-bearing segmental defects should offer sufficient support to withstand mechanical loading (Giannoudis et al., 2011). A material with such mechanical properties is titanium, and solid titanium implants have been very successfully used in trauma and orthopaedic surgery over the past decades (Learmonth et al., 2007). However, the notable biomechanical mismatch between solid titanium implants and surrounding bone frequently leads to stress-shielding, subsequent bone resorption and implant loosening (Niinomi, 2008). This limitation can be overcome by using mechanically optimised porous titanium implants (Murr et al., 2011; Ryan et al., 2009), the development of which greatly benefited from the introduction of additive manufacturing techniques. Techniques such as selective laser melting
(Hollander et al., 2006; Mullen et al., 2009; Stamp et al., 2009), electron beam melting (EBM) (Heinl et al., 2008; Hrabe et al., 2011; Ponader et al., 2010) or similar additive manufacturing techniques (Bandyopadhyay et al., 2010; Bandyopadhyay et al., 2009) allow for a personalised, anatomical implant design and control of its structural and mechanical properties alike. Our SLM-based, femurshaped implants possessed mechanical properties within the physiological range of the host bone, while its fully interconnected porous structure is considered to be within the range required for osteoconduction (Table 1) (Van der Stok et al., 2013a). Furthermore, the fatigue properties of the porous implants indicate that the biomechanical support is temporary (Amin Yavari et al., 2013). The implants were therefore capable of offering sufficient mechanical support in vivo, while stimulating bone regeneration through osteoconduction in the segmental bone defects (Van der Stok et al., 2013a; Van der Stok et al., 2013b).

In addition to mechanical support, biomaterials should also offer a surface that facilities osseointegration, i.e. intimate apposition of bone matrix onto the implant surface (Puleo and Nanci, 1999). The bone-implant interface of most metallic biomaterials including titanium usually consists of an interfacial fibrous-like layer (also called 
laminae limitantes) (Puleo and Nanci, 1999). The formation of this fibrous-like layer can be avoided by relatively simple treatments that have been shown to improve osseointegration of solid titanium implants (Wennerberg and Albrektsson, 2009). We optimised the treatment of the porous titanium implants used in this study (Amin Yavari et al., 2014b), to not only improve apatite formation and cellular attachment, but also cell proliferation and osteogenic differentiation of osteoprogenitor cells (Amin Yavari et al., 2014b).

Bone graft substitutes should also be able to induce bone regeneration, which can be induced by a variety of bone morphogenetic proteins (BMPs), including BMP-2 and BMP-7 (Groeneveld and Burger, 2000). BMP-2 is mainly released during the first few days of the natural bone regeneration process, and BMP-7 plays a more important role during the later phase (Gerstenfeld et al., 2003). Both BMP-2 and BMP-7 received FDA-approval (Termaat et al., 2005), but their use in humans is currently heavily debated (Carragee et al., 2011). Although the osteoinductive effect of BMP-2 has been demonstrated in a wide variety of species (including rats, rabbits, dogs, sheep and non-human primates) (An and Friedman, 1999), it is often argued that one must be cautious in assuming that stromal cells from other species may serve as models for inducible osteogenesis in human marrow stromal cells (Diefenderfer et al., 2003). BMP-induced side effects, including cyst-like bone formation and soft tissue swelling, are likely caused by supra-physiological dosages used in humans (Carragee et al., 2011) and these adverse effects were recently reproduced in a similar in vivo model as used in this study with BMP-2 concentrations exceeding $20 \mu \mathrm{g}$ per defect (Angle et al., 2012; Zara et al., 2011). In contrast, a dose between 2.5 and $10 \mu \mathrm{g}$ was found to be safe and effective for various other BMP release systems including alginate-based (Boerckel et al., 2011), poly-Llactic acid (PLLA)-based (Wei et al., 2007) or silk-based (Bessa et al., 2010) scaffolds. Based on these results we used $3 \mu \mathrm{g}$ BMP-2 per implant. Furthermore, Schmoekel et al. demonstrated that with less soluble nonglycosylated BMP-2, the required cytokine dose could even be further reduced (Schmoekel et al., 2004).

Surface-treated porous titanium was loaded with BMP2 through incorporation in physiologically concentrated fibrin gels. This is different from fibrin gels that have been used in trauma and orthopaedic surgery as "fibrin glue", as these sealants are made of highly supra-physiological fibrinogen concentrations (Janmey et al., 2009). This supra-physiological concentration $(50-100 \mathrm{mg} / \mathrm{L})$ ensures quick and effective clotting, and is therefore primarily used as a haemostatic agent. Supra-physiological fibrinogen concentrations were also used to deliver BMP-2 in several bone defect models (Chung et al., 2007; Kaipel et al., 2012; Kim et al., 2008; Koo et al., 2013; Koo et al., 2012; La et al., 2012; Schmoekel et al., 2004; Schmokel et al., 2004; Schutzenberger et al., 2012; Yang et al., 2010; Yang et al., 2012). Schützenberger et al. showed that fibrin gels outperformed the currently clinically used absorbable collagen sponges as BMP-release properties of fibrin, in contrast to those of collagen, allow to use $85 \%$ less cytokine without compromising the regenerative success (Schutzenberger et al., 2012). However, the high fibrinogen concentration of these supra-physiologically concentrated fibrin glues have a limiting effect on cell mobility and ingrowth (Nürnberger et al., 2010; Peterbauer-Scherb et al., 2012). In vivo, fibrin constitutes only $0.25 \%$ of the volume of a blood clot (Weisel, 2004), which was mimicked in the current study by preparing fibrin gels of physiological concentrations $(2-4 \mathrm{mg} / \mathrm{L})$. It is tempting to speculate that at these concentrations, fibrin fibres form a more open network that more effectively promoted cell migration and cell ingrowth (Seebach et al., 2014). This open network structure and fibrin fibre adherence was perfectly supported by the surface-treated porous titanium (Fig. 1c). This temporary fibrin network is not expected to remain intact in vivo for more than a few days (Schmokel et al., 2004), but the results obtained in this study suggest that this is sufficient to adequately induce bone regeneration. Our approach mimics physiological fracture healing, during which BMP-2 is entrapped in the spontaneously formed fracture haematoma to induce differentiation of mesenchymal stem cells into osteoblasts (Onishi et al., 1998). These osteoblast subsequently start to produce more BMP-2 and other important osteogenic cytokines to reach a maximum activity after 4-7 days (Kirker-Head, 1995).

Physiologically concentrated fibrin gels prepared from HMW fibrinogen were expected to improve bone regeneration, as compared to gels prepared from UNF fibrinogen, because HMW fibrinogen has been shown to promote angiogenesis in vitro and in vivo in our earlier studies (Kaijzel et al., 2006). UNF fibrin gels contain $30 \%$ low molecular weight fibrinogen and, compared to $100 \%$ HMW fibrinogen, contamination with more than $10 \%$ of LMW fibrinogen gradually decreased the formation of tube-like structure in vitro in a dose-depend manner (Kaijzel et al., 2006). However, implants with $\mathrm{HMW}-\mathrm{Fb}$ gels alone did not enhance bone regeneration and performed similar to implants with UNF-Fb gels or empty porous titanium implants (Fig. 2 and 5). BMP-2 release from the fibrin gel is apparently providing the only osteoinductive stimulus, while HMW-Fb may still improve cell migration and angiogenesis. Whether using $\mathrm{HMW}-\mathrm{Fb}$ to release BMP-2 is better than using UNF-Fb cannot be answered here and is a limitation of our study. However, HMW-fibrin gels with BMP-2 clearly outperformed previously used gelatin-based nanosphere gels with BMP-2 (Van der Stok et al., 2013b), indicating the type of BMP2 carrier is of crucial importance. Although gelatin gels were capable of a sustained release of BMP-2 (Wang et al., 2013), this resulted in bone regeneration that mainly occurred around and inside the porous titanium implants (Fig. 8, a1). In addition, bone regeneration in that study did not lead to bridging of the grafted defects within twelve weeks (Fig. 8, b1). The mechanical strength also reached up to only $50 \%$ of the original strength in that study (Wang et al., 2013). In contrast, physiological fibrin gels with low doses of BMP-2 boosted bone regeneration in the present study and completely bridged the majority of the grafted defects within four weeks (Fig. 8, b2), filling up more than $50 \%$ of the porous volume of the titanium implants with 
regenerated bone. Twelve weeks following the surgery, the grafted femora were already more than twice as strong as their original strength (i.e. control femora Fig. 6).

\section{Conclusion}

This study reports the development of a new biomaterial combination, capable of stimulating complete bone regeneration in load-bearing segmental defects in rat femora. This optimal combination enabled quick bone regeneration within four weeks and full restoration of the original bone functionality and anatomical shape in this pre-clinical model. Since all used methods have been used separately in trauma and orthopaedic surgery, this combination should be evaluated in a large animal model or a clinical trial and this might result in an efficient bone graft substitute to graft load-bearing segmental bone defects in trauma and orthopaedic surgery.

\section{Acknowledgements}

This research forms part of the Project P2.04 BONE-IP of the research program of the BioMedical Materials institute, co-funded by the Dutch Ministry of Economic Affair and was supported by a grant from the Dutch government to The Netherlands Institute for Regenerative Medicine (NIRM, grant No. FES0908). This research project was further supported by the START-Program of the Faculty of Medicine, RWTH Aachen. Osteosynthesis \& Trauma Care foundation is acknowledged for financial support (2011-HWJV).

\section{References}

Alvarez K, Nakajima H (2009) Metallic scaffolds for bone regeneration. Materials 2: 790-832.

Amin Yavari S, Ahmadi SM, Van der Stok J, Wauthle R, Riemslag AC, Janssen M, Schrooten J, Weinans H, Zadpoor AA (2014a) Effects of bio-functionalizing surface treatments on the mechanical behavior of open porous titanium biomaterials. J Mech Behav Biomed Mater 36:109-119.

Amin Yavari S, van der Stok J, Chai YC, Wauthle R, Tahmasebi Birgani Z, Habibovic P, Mulier M, Schrooten J, Weinans H, Zadpoor AA (2014b) Bone regeneration performance of surface-treated porous titanium. Biomaterials 35: 6172-6181.

Amin Yavari S, Wauthle R, van der Stok J, Riemslag AC, Janssen M, Mulier M, Kruth JP, Schrooten J, Weinans H, Zadpoor AA (2013) Fatigue behavior of porous biomaterials manufactured using selective laser melting. Mater Sci Eng C Mater Biol Appl 33: 4849-4858.

An YH, Friedman RJ (1999) Animal models in orthopaedic research. CRC Press, New York.
Angle SR, Sena K, Sumner DR, Virkus WW, Virdi AS (2012) Healing of rat femoral segmental defect with bone morphogenetic protein-2: a dose response study. J Musculoskelet Neuronal Interact 12: 28-37.

Bandyopadhyay A, Espana F, Balla VK, Bose S, Ohgami Y, Davies NM (2010) Influence of porosity on mechanical properties and in vivo response of Ti6Al4V implants. Acta Biomater 6: 1640-1648.

Bandyopadhyay A, Krishna BV, Xue W, Bose S (2009) Application of laser engineered net shaping (LENS) to manufacture porous and functionally graded structures for load bearing implants. J Mater Sci Mater Med 20 Suppl 1: S29-34.

Banwart JC, Asher MA, Hassanein RS (1995) Iliac crest bone graft harvest donor site morbidity. A statistical evaluation. Spine (Phila Pa 1976) 20: 1055-1060.

Bessa PC, Balmayor ER, Hartinger J, Zanoni G, Dopler D, Meinl A, Banerjee A, Casal M, Redl H, Reis RL, van Griensven M (2010) Silk fibroin microparticles as carriers for delivery of human recombinant bone morphogenetic protein-2: in vitro and in vivo bioactivity. Tissue Eng Part C Methods 16: 937-945.

Boerckel JD, Kolambkar YM, Dupont KM, Uhrig BA, Phelps EA, Stevens HY, Garcia AJ, Guldberg RE (2011) Effects of protein dose and delivery system on BMPmediated bone regeneration. Biomaterials 32: 5241-5251.

Carragee EJ, Hurwitz EL, Weiner BK (2011) A critical review of recombinant human bone morphogenetic protein-2 trials in spinal surgery: emerging safety concerns and lessons learned. Spine J 11: 471-491.

Cho TJ, Gerstenfeld LC, Einhorn TA(2002) Differential temporal expression of members of the transforming growth factor beta superfamily during murine fracture healing. J Bone Miner Res 17: 513-520.

Chung YI, Ahn KM, Jeon SH, Lee SY, Lee JH, Tae G (2007) Enhanced bone regeneration with BMP-2 loaded functional nanoparticle-hydrogel complex. J Control Release 121: 91-99.

de Wild M, Schumacher R, Mayer K, Schkommodau E, Thoma D, Bredell M, Kruse Gujer A, Gratz KW, Weber FE (2013) Bone regeneration by the osteoconductivity of porous titanium implants manufactured by selective laser melting: a histological and micro computed tomography study in the rabbit. Tissue Eng Part A 19: 2645-2654.

Diefenderfer DL, Osyczka AM, Garino JP, Leboy PS (2003) Regulation of BMP-induced transcription in cultured human bone marrow stromal cells. J Bone Joint Surg Am 85-A Suppl 3: 19-28.

Einhorn TA (1995) Enhancement of fracture-healing. J Bone Joint Surg Am 77: 940-956.

Gerstenfeld LC, Cullinane DM, Barnes GL, Graves DT, Einhorn TA (2003) Fracture healing as a post-natal developmental process: molecular, spatial, and temporal aspects of its regulation. J Cell Biochem 88: 873-884.

Giannoudis PV, Chris Arts JJ, Schmidmaier G, Larsson S (2011) What should be the characteristics of the ideal bone graft substitute? Injury 42 Suppl 2: S1-2.

Groeneveld EH, Burger EH (2000) Bone morphogenetic proteins in human bone regeneration. Eur J Endocrinol 142: 9-21. 
Heinl P, Muller L, Korner C, Singer RF, Muller FA (2008) Cellular Ti-6Al-4V structures with interconnected macro porosity for bone implants fabricated by selective electron beam melting. Acta Biomater 4: 1536-1544.

Hollander DA, von Walter M, Wirtz T, Sellei R, Schmidt-Rohlfing B, Paar O, Erli HJ (2006) Structural, mechanical and in vitro characterization of individually structured Ti-6Al-4V produced by direct laser forming. Biomaterials 27: 955-963.

Holm B, Nilsen DW, Kierulf P, Godal HC (1985) Purification and characterization of 3 fibrinogens with different molecular weights obtained from normal human plasma. Thromb Res 37: 165-176.

Hrabe NW, Heinl P, Flinn B, Korner C, Bordia RK (2011) Compression-compression fatigue of selective electron beam melted cellular titanium (Ti-6Al-4V). J Biomed Mater Res B Appl Biomater 99: 313-320.

Janmey PA, Winer JP, Weisel JW (2009) Fibrin gels and their clinical and bioengineering applications. J R Soc Interface 6: 1-10.

Kaijzel EL, Koolwijk P, van Erck MG, van Hinsbergh VW, de Maat MP (2006) Molecular weight fibrinogen variants determine angiogenesis rate in a fibrin matrix in vitro and in vivo. J Thromb Haemost 4: 1975-1981.

Kaipel M, Schutzenberger S, Schultz A, Ferguson J, Slezak P, Morton TJ, Van Griensven M, Redl H (2012) BMP-2 but not VEGF or PDGF in fibrin matrix supports bone healing in a delayed-union rat model. J Orthop Res 30: $1563-1569$.

Khan SN, Lane JM (2004) The use of recombinant human bone morphogenetic protein-2 (rhBMP-2) in orthopaedic applications. Expert Opin Biol Ther 4: 741 748.

Kim SS, Gwak SJ, Kim BS (2008) Orthotopic bone formation by implantation of apatite-coated poly(lactideco-glycolide)/hydroxyapatite composite particulates and bone morphogenetic protein-2. J Biomed Mater Res A 87: 245-253.

Kirker-Head CA (1995) Recombinant bone morphogenetic proteins: novel substances for enhancing bone healing. Vet Surg 24: 408-419.

Koo KH, Lee JM, Ahn JM, Kim BS, La WG, Kim CS, Im GI (2013) Controlled delivery of low-dose bone morphogenetic protein-2 using heparin-conjugated fibrin in the posterolateral lumbar fusion of rabbits. Artif Organs 37: 487-494.

Koo KH, Yeo do H, Ahn JM, Kim BS, Kim CS, Im GI (2012) Lumbar posterolateral fusion using heparin-conjugated fibrin for sustained delivery of bone morphogenic protein-2 in a rabbit model. Artif Organs 36: 629-634.

La WG, Kwon SH, Lee TJ, Yang HS, Park J, Kim BS (2012) The effect of the delivery carrier on the quality of bone formed via bone morphogenetic protein-2. Artif Organs 36: 642-647.

Langer R, Vacanti JP (1993) Tissue engineering. Science 260: 920-926.

Learmonth ID, Young C, Rorabeck C (2007) The operation of the century: total hip replacement. Lancet 370: 1508-1519.
Martino MM, Briquez PS, Ranga A, Lutolf MP, Hubbell JA (2013) Heparin-binding domain of fibrin(ogen) binds growth factors and promotes tissue repair when incorporated within a synthetic matrix. Proc Natl Acad Sci U S A 110: 4563-4568.

Milleret V, Tugulu S, Schlottig F, Hall H (2011) Alkali treatment of microrough titanium surfaces affects macrophage/monocyte adhesion, platelet activation and architecture of blood clot formation. Eur Cell Mater 21: 430-444.

Mullen L, Stamp RC, Brooks WK, Jones E, Sutcliffe CJ (2009) Selective Laser Melting: a regular unit cell approach for the manufacture of porous, titanium, bone in-growth constructs, suitable for orthopedic applications. J Biomed Mater Res B Appl Biomater 89: 325-334.

Murakami N, Saito N, Horiuchi H, Okada T, Nozaki K, Takaoka K (2002) Repair of segmental defects in rabbit humeri with titanium fiber mesh cylinders containing recombinant human bone morphogenetic protein-2 (rhBMP-2) and a synthetic polymer. J Biomed Mater Res 62: 169-174.

Murr LE, Amato KN, Li SJ, Tian YX, Cheng XY, Gaytan SM, Martinez E, Shindo PW, Medina F, Wicker RB (2011) Microstructure and mechanical properties of opencellular biomaterials prototypes for total knee replacement implants fabricated by electron beam melting. J Mech Behav Biomed Mater 4: 1396-1411.

Murr LE, Gaytan SM, Medina F, Lopez H, Martinez E, Machado BI, Hernandez DH, Martinez L, Lopez MI, Wicker RB, Bracke J (2010) Next-generation biomedical implants using additive manufacturing of complex, cellular and functional mesh arrays. Philos Trans A Math Phys Eng Sci 368: 1999-2032.

Niinomi M (2008) Mechanical biocompatibilities of titanium alloys for biomedical applications. J Mech Behav Biomed Mater 1: 30-42.

Nürnberger S, Wolbank S, Peterbauer-Scherb A, Morton TJ, Feichtinger GA, Gugerell A, Meinl A, Labuda K, Bittner M, Pasteiner W, Nikkola L, Gabriel C, van Griensven M, Redl H (2010) Properties and potential alternative applications in fibrin glue. In Biological Adhesive Systems Ed. J. von Byern and I. Grunwald, Springer, Wien, 237-259.

Onishi T, Ishidou Y, Nagamine T, Yone K, Imamura T, Kato M, Sampath TK, ten Dijke P, Sakou T (1998) Distinct and overlapping patterns of localization of bone morphogenetic protein (BMP) family members and a BMP type II receptor during fracture healing in rats. Bone 22: 605-612.

Pape HC, Evans A, Kobbe P (2010) Autologous bone graft: properties and techniques. J Orthop Trauma 24 Suppl 1: S36-40.

Peterbauer-Scherb A, Danzer M, Gabriel C, van Griensven M, Redl H, Wolbank S (2012) In vitro adipogenesis of adipose-derived stem cells in 3D fibrin matrix of low component concentration. J Tissue Eng Regen Med 6: 434-442.

Ponader S, von Wilmowsky C, Widenmayer M, Lutz R, Heinl P, Korner C, Singer RF, Nkenke E, Neukam FW, Schlegel KA (2010) In vivo performance of selective 
electron beam-melted Ti-6Al-4V structures. J Biomed Mater Res A 92: 56-62.

Puleo DA, Nanci A (1999) Understanding and controlling the bone-implant interface. Biomaterials 20: 2311-2321.

Ryan G, McGarry P, Pandit A, Apatsidis D (2009) Analysis of the mechanical behavior of a titanium scaffold with a repeating unit-cell substructure. J Biomed Mater Res B Appl Biomater 90: 894-906.

Ryan G, Pandit A, Apatsidis DP (2006) Fabrication methods of porous metals for use in orthopaedic applications. Biomaterials 27: 2651-2670.

Schmoekel H, Schense JC, Weber FE, Gratz KW, Gnagi D, Muller R, Hubbell JA (2004) Bone healing in the rat and dog with nonglycosylated BMP-2 demonstrating low solubility in fibrin matrices. J Orthop Res 22: 376-381.

Schmokel HG, Weber FE, Seiler G, von Rechenberg B, Schense JC, Schawalder P, Hubbell J (2004) Treatment of nonunions with nonglycosylated recombinant human bone morphogenetic protein-2 delivered from a fibrin matrix. Vet Surg 33: 112-118.

Schutzenberger S, Schultz A, Hausner T, Hopf R, Zanoni G, Morton T, Kropik K, van Griensven M, Redl H (2012) The optimal carrier for BMP-2: a comparison of collagen versus fibrin matrix. Arch Orthop Trauma Surg 132: 1363-1370.

Seebach E, Freischmidt H, Holschbach J, Fellenberg J, Richter W (2014) Mesenchymal stroma cells trigger early attraction of M1 macrophages and endothelial cells into fibrin hydrogels, stimulating long bone healing without long-term engraftment. Acta Biomater 10: 4730-4741.

Senta H, Park H, Bergeron E, Drevelle O, Fong D, Leblanc E, Cabana F, Roux S, Grenier G, Faucheux N (2009) Cell responses to bone morphogenetic proteins and peptides derived from them: biomedical applications and limitations. Cytokine Growth Factor Rev 20: 213-222.

Stamp R, Fox P, O’Neill W, Jones E, Sutcliffe C (2009) The development of a scanning strategy for the manufacture of porous biomaterials by selective laser melting. J Mater Sci Mater Med 20: 1839-1848.

Termaat MF, Den Boer FC, Bakker FC, Patka P, Haarman HJ (2005) Bone morphogenetic proteins. Development and clinical efficacy in the treatment of fractures and bone defects. J Bone Joint Surg Am 87: 1367-1378.

Unger S, Blauth M, Schmoelz W (2010) Effects of three different preservation methods on the mechanical properties of human and bovine cortical bone. Bone 47: 1048-1053.

Urist MR (1965) Bone: formation by autoinduction. Science 150: 893-899.

Van der Stok J, Van der Jagt OP, Amin Yavari S, De Haas MF, Waarsing JH, Jahr H, Van Lieshout EEM, Patka P, Verhaar JA, Zadpoor AA, Weinans H (2013a) Selective laser melting-produced porous titanium scaffolds regenerate bone in critical size cortical bone defects. J Orthop Res 31: 792-799.

Van der Stok J, Wang H, Amin Yavari S, Siebelt M, Sandker M, Waarsing JH, Verhaar JA, Jahr H, Zadpoor AA, Leeuwenburgh SC, Weinans H (2013b) Enhanced bone regeneration of cortical segmental bone defects using porous titanium scaffolds incorporated with colloidal gelatin gels for time- and dose-controlled delivery of dual growth factors. Tissue Eng Part A 19: 23-24.

Wang H, Zou Q, Boerman OC, Nijhuis AW, Jansen JA, Li Y, Leeuwenburgh SC (2013) Combined delivery of BMP-2 and bFGF from nanostructured colloidal gelatin gels and its effect on bone regeneration in vivo. J Control Release 166: 172-181.

Wei G, Jin Q, Giannobile WV, Ma PX (2007) The enhancement of osteogenesis by nano-fibrous scaffolds incorporating rhBMP-7 nanospheres. Biomaterials 28: 2087-2096.

Weisel JW (2004) The mechanical properties of fibrin for basic scientists and clinicians. Biophys Chem 112: 267-276.

Wennerberg A, Albrektsson T (2009) Effects of titanium surface topography on bone integration: a systematic review. Clin Oral Implants Res 20 Suppl 4: 172-184.

Woo EJ (2013) Adverse events after recombinant human BMP2 in nonspinal orthopaedic procedures. Clin Orthop Relat Res 471: 1707-1711.

Yang HS, La WG, Bhang SH, Jeon JY, Lee JH, Kim BS (2010) Heparin-conjugated fibrin as an injectable system for sustained delivery of bone morphogenetic protein-2. Tissue Eng Part A 16: 1225-1233.

Yang HS, La WG, Cho YM, Shin W, Yeo GD, Kim BS (2012) Comparison between heparin-conjugated fibrin and collagen sponge as bone morphogenetic protein- 2 carriers for bone regeneration. Exp Mol Med 44: 350-355.

Zara JN, Siu RK, Zhang X, Shen J, Ngo R, Lee M, Li W, Chiang M, Chung J, Kwak J, Wu BM, Ting K, Soo C (2011) High doses of bone morphogenetic protein 2 induce structurally abnormal bone and inflammation in vivo. Tissue Eng Part A 17: 1389-1399.

\section{Discussion with Reviewers}

Reviewer I: How can such an implant be fixed? In addition, can the fixation be integral part of the construct?

Authors: This is an intriguing question and obviously an important aspect of implant development. Because porous titanium implants are developed using selective laser melting (an additive manufacturing technique) options for screw or pin fixation can be completely integrated into the implant design. Examples of porous implants designs are more thoroughly described by Murr (Murr et al, 2010).

Reviewer II: When you look more than 12 weeks, may it be possible that the titanium mesh is impairing further bone formation as it is not degrading?

Authors: Bone formation would be impaired if implantation of the porous titanium implants result in a significant mechanical mismatch with the surrounding bone. This could cause stress shielding and subsequent bone resorption. However, extensive mechanical testing of the produced porous titanium indicated that due to fatigue the implants will lose some of their initial strength over time (Amin Yavari et al., 2013). This gradual weakening of the implants will avoid stress-shielding and is more likely 
to stimulate bone formation rather than impairing bone formation. The main disadvantage of the fact that titanium implants do not degrade is the long-term risk of infection.

Reviewer III: Is this laboriously produced fibrin much better than commercially available material?

Authors: That may depend on the application. We have already shown that HMW-Fb stimulates angiogenesis in vitro (Kaijzel et al, 2006). As our commercial UNF-Fb does not behave much differently from HMW-Fb, with respect to bone bridging, we cannot clearly answer this for the present study. However, our novel combination of a fibrin gel within a highly porous titanium implant results in very good bone regeneration - at least when using $\mathrm{HMW}-\mathrm{Fb}$ with low doses of BMP-2. The limitations of this study are now thoroughly addressed. 